\title{
Residue level and health risk assessment of organophosphorus pesticides in eggplant and cauliflower collected from Dhaka city, Bangladesh
}

\author{
${ }^{1}$ Habib, M., ${ }^{1,2}$ Kaium, A., ${ }^{1}$ Khan, M.S.I., ${ }^{3}$ Prodhan, M.D.H., ${ }^{1}$ Begum, N., \\ ${ }^{1}$ Chowdhury, M.T.I. and ${ }^{1, *}$ Islam, M.A. \\ ${ }^{1}$ Department of Agricultural Chemistry, Faculty of Agriculture, Sher-e-Bangla Agricultural University, \\ Dhaka-1207, Bangladesh \\ ${ }^{2}$ State Key Laboratory for Biology of Plant Disease and Insect Pests, Institute of Plant Protection, Chinese \\ Academy of Agricultural Sciences, Beijing-100193, China \\ ${ }^{3}$ Pesticide Research and Environmental Toxicology Section, Entomology Division, Bangladesh Agricultural \\ Research Institute, Gazipur-1701, Bangladesh
}

\begin{abstract}
Article history: January 2021 2021

\section{Keywords:}

Organophosphorus,

Residue level,

Risk assessment,

Eggplant,

Cauliflower,

GC-FTD
\end{abstract}

Received: 30 November 2020 Received in revised form: 1

Accepted: 22 February 2021 Available Online: 27 June

\section{DOI:}

https://doi.org/10.26656/fr.2017.5(3).624

\begin{abstract}
Residue levels of seven organophosphorus pesticides in two vegetables (eggplant and cauliflower) collected from major markets of Dhaka city, Bangladesh were analysed. The collected samples were analysed using a modified Quick, Easy, Cheap, Effective, Rugged, and Safe (QuEChERS) extraction technique by Gas Chromatography coupled with Flame Thermionic Detector (GC-FTD). Among the 50 analysed samples of the eggplant $12 \%$ samples contained residues of chlorpyrifos $(0.384 \sim 0.980 \mathrm{mg} / \mathrm{kg}), 6 \%$ samples contained residue of dimethoate $(0.052 \sim 0.132 \mathrm{mg} / \mathrm{kg})$ and $2 \%$ samples contained residue of diazinon $(0.01 \mathrm{mg} / \mathrm{kg})$. Whereas, among the 50 samples of cauliflower, $12 \%$ samples contained residues of chlorpyrifos $(0.056 \sim 0.540 \mathrm{mg} / \mathrm{kg}), 8 \%$ samples contained residues of diazinon $(0.033 \sim 0.42 \mathrm{mg} / \mathrm{kg})$ and $2 \%$ samples contained residues of quinalphos $(0.06 \mathrm{mg} / \mathrm{kg})$. The chlorpyrifos was found as the most frequently detected organophosphorus pesticide. Among the 21 contaminated samples, 20 were above EU-MRL. Short and long-term health risk assessment based on ARfD and ADI indicates that the intake risks of eggplant and cauliflower were in the acceptable range. Nevertheless, establishing strong monitoring and traceability system together with controlling pre-harvest interval needed to ensure food safety, consumer confidence and promote vegetable export from Bangladesh.
\end{abstract}

\section{Introduction}

Organophosphorus pesticides (OPPs) are organic derivatives of phosphoric acid, phosphonic acid, phosphorothioic acid, or phosphonothioic acids (Corbett, 1974; Espinoza-Navarro et al., 2017; Eco and Zweig, 2018). Up until now, Organophosphorus pesticides are one of the most commonly used pesticide classes in agriculture in the management of insect pests due to their high efficacy, comparatively high dissipation, and low persistence compared to other pest class pesticides (González-Curbelo et al., 2012; Eco and Zweig, 2018). More often, pesticides are misused, including overdoses, adulterated formulas, and harvesting without a minimum waiting period (Herrera-Herrera et al., 2019). The extensive use of pesticides can contaminate both the atmosphere and food, leading to health problems (Sultana and Nakagoshi, 2001; Islam et al., 2009). In OPPs, extensive exposure to higher concentrations can lead to cardiovascular, nervous, respiratory, metabolic, reproductive, and even immune symptoms problems (Joshi and Sharma, 2011; Espinoza-Navarro et al., 2017). Besides, these groups of compounds are likely to change embryonic health and lead children to ADHD (Hassani et al., 2017). The toxicity of OPPs metabolites is much more toxic than the parent compound itself. Thus, OPPs are known to be the most toxic class of pesticides in insects, animals, and humans (Hassani et al., 2017). According to the USA pesticide usage database, the most frequently used OPPs are malathion, dimethoate, chlorpyrifos, acephate, naled, diazinon, methyl-parathion, dicrotophos, phorate, phosmet, and azinphos-methyl (Grube et al., 2011). In the developing world, pesticide selection is mostly older, broadspectrum, organophosphate and carbamate class, because of their acute toxicity and they are also cheaper than the newer types (Sultana and Nakagoshi, 2001). 
Bangladesh is a land of agriculture and many farmers cultivate vegetables in their home garden and in the field on a commercial basis (Chowdhury et al., 2011). In Bangladesh, eggplant and cauliflower are one of the healthiest, most nutritious, a widely consumed vegetable as it is available all year round and has an attractive taste (BARI, 2013; Amin et al., 2018). In Bangladesh, farmers have frequently used pesticides to ensure the quality and higher yields of vegetables (Dasgupta et al., 2007). The most alarming concern is that farmers of Bangladesh often spray hazardous pesticide like OPPs up to five to six times than the recommended dosage in one crop growing season (Sultana and Nakagoshi, 2001; Dasgupta et al., 2007). In recent years, eggplant and cauliflower cultivation have become expensive and risky for farmers and consumers due to the increased use of chemical pesticides to control pests (Srinivasan, 2008). Also, in most areas of Bangladesh, vegetables are marketed without maintaining a pre-harvest interval period. These market vegetables often contain pesticide residues due to overuse on the farm, which has adverse effects on human health (Dasgupta et al., 2007; Chowdhury et al., 2011; Nahar et al., 2020). A study found that eggplant is the most pesticide residue contained vegetable, which is the reason for the vegetable export reduction (Islam et al., 2014). In order to ensure consumer safety, most countries have established a maximum residue limit (MRL) and an acceptable daily intake (ADI) of pesticide residues in food items (Chowdhury et al., 2011). The impact of daily intakes of pesticide residues in food should be measured by an exposure or risk assessment.

In the present study, seven mostly used organophosphorus pesticides (acephate, chlorpyrifos, diazinon, dimethoate, fenitrothion, malathion, and quinalphos) were selected to determine the level of residues in eggplant and cauliflower marketed in Dhaka city, Bangladesh. This study also aimed to assess the short-term and long long-term health risks to consumers posed by these pesticide residues.

\section{Materials and methods}

\subsection{Chemicals}

The standard $(>99.6 \%$ pure $)$ of acephate, chlorpyrifos, diazinon, dimethoate, fenitrothion, malathion, and quinalphos were purchased from SigmaAldrich (St Louis, MO, USA) via Bangladesh Scientific Pvt. Ltd. Dhaka, Bangladesh. Analytical grade methanol, acetone, HPLC grade acetonitrile, sodium chloride $(\mathrm{NaCl})$, anhydrous magnesium sulfate $\left(\mathrm{MgSO}_{4}\right)$, and Primary Secary Amine (PSA) were purchased from Bangladesh Scientific Pvt. Ltd.

\subsection{Study area}

The study area included five major markets of Dhaka city, the capital of Bangladesh (Figure 1). It is one of the biggest megacities with 20 million peoples and located in the central point of the country. This study was conducted by collecting eggplant and cauliflower for pesticide residues from major vegetable markets of Dhaka city. The Kawran Bazar, Mohammadpur Krishi Market, Mirpur-1 Bazar, Taltola Bazar and Jatrabari Bazar were considered for sample selection. These markets are famous for vegetables and other daily shopping in Dhaka city. These market vegetables are grown in different districts and certain parts of the neighbouring areas.

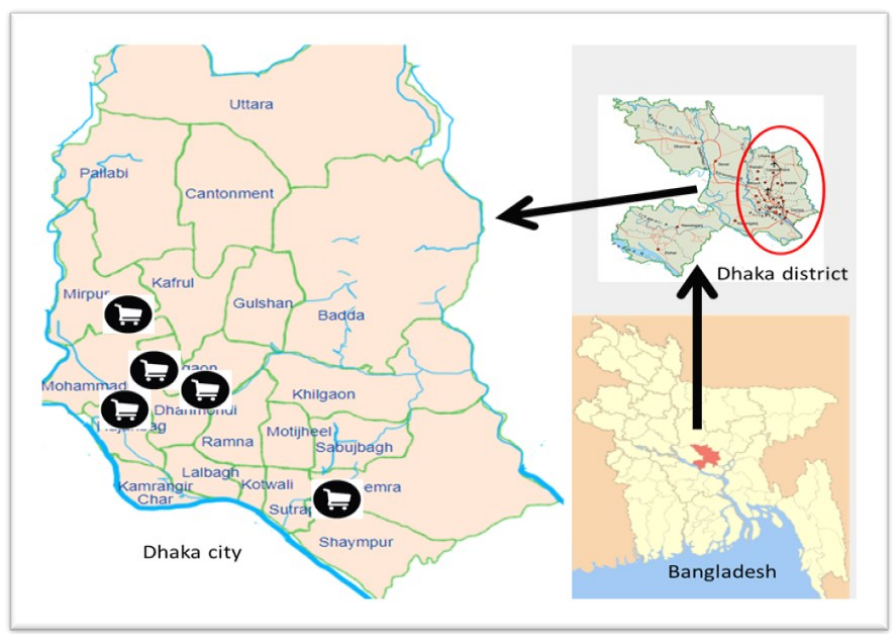

Figure 1. Map showing the places of sample collection in the Dhaka city

\subsection{Sample collection}

A total of 100 samples were collected (50 eggplants and 50 cauliflower). Ten eggplant samples and ten cauliflower samples were collected from each market (Kawran Bazar, Mohammadpur Krishi Market, Mirpur-1 Bazar, Taltola Bazar and Jatrabari Bazar) in Dhaka city. The amount of each vegetable samples was $1 \mathrm{~kg}$. The samples were collected in individual polythene bags, and each bag has been appropriately labelled with the sample numbers and sources. The collected samples were transported on collection day to the Pesticide Analytical Laboratory of Bangladesh Agricultural Research Institute (BARI), Gazipur. Each sample was cut into small pieces and appropriately mixed for homogeneity. Then, the chopped samples were processed at $-20^{\circ} \mathrm{C}$ using airtight zipper bags before the extraction and clean -up process started.

\subsection{Preparation of pesticide standard solution}

Pesticide standard stock solutions of acephate, chlorpyrifos, diazinon, dimethoate, fenitrothion, 
malathion, and quinalphos were prepared separately in acetone at a concentration of $1000 \mathrm{mg} / \mathrm{L}$ and stored at $20^{\circ} \mathrm{C}$ until use. A mixed standard solution of $50 \mathrm{mg} / \mathrm{L}$ in acetone containing all the pesticides, as mentioned above, was prepared by adding the appropriate volume of each stock solution in a $50 \mathrm{~mL}$ volumetric flask and made to the volume by adding acetone. An intermediate mixed standard solution of $10 \mathrm{mg} / \mathrm{L}$ in acetone was prepared from the mixed standard solution of $50 \mathrm{mg} / \mathrm{L}$. Then working standard solutions of $0.1,0.2,0.5,1.0,2.0$, 3.0 , and $5.0 \mathrm{mg} / \mathrm{L}$ in acetone were prepared by transferring the appropriate amount from $10 \mathrm{mg} / \mathrm{L}$ intermediate mixed standard solution into ten separate 10 $\mathrm{mL}$ volumetric flasks. All the standard solutions were kept in a freezer at $-20^{\circ} \mathrm{C}$ until use.

\subsection{Extraction and clean-up}

In this study, the modified QuEChERS extraction technique was used to extract and cleanup the collected vegetable samples (Prodhan et al., 2015). The chopped vegetable samples were grounded thoroughly with a blender. A representative $10 \mathrm{~g}$ portion of the thoroughly homogenized sample was weighted in a $50 \mathrm{~mL}$ polypropylene centrifuge tube. Then $10 \mathrm{~mL}$ of acetonitrile $\left(\mathrm{CH}_{3} \mathrm{CN}\right)$ was added into the centrifuge tube. The centrifuge tube was appropriately closed and shaken vigorously for 30 secs by using a vortex mixer. Then, $4 \mathrm{~g}$ of anhydrous $\mathrm{MgSO}_{4}$ and $1 \mathrm{~g}$ of $\mathrm{NaCl}$ were added into the centrifuge tube, and it was shaken immediately by the vortex mixer for $1 \mathrm{~min}$ to prevent the formation of magnesium sulfate aggregates. Afterwards, the extract was centrifuged for $5 \mathrm{mins}$ at $5000 \mathrm{rpm}$. An aliquot of 3 $\mathrm{mL}$ of the $\mathrm{CH}_{3} \mathrm{CN}$ layer was transferred into a $15 \mathrm{~mL}$ centrifuge tube containing $600 \mathrm{mg}$ anhydrous $\mathrm{MgSO}_{4}$ and $120 \mathrm{mg}$ Primary Secary Amine (PSA). Then it was thoroughly mixed by vortex for 30 secs and centrifuged for 5 mins at $4000 \mathrm{rpm}$ (Laboratory Centrifuges, Sigma3K30, Germany). After centrifuge, a $1 \mathrm{~mL}$ supernatant was filtered by a $0.2 \mu \mathrm{m}$ PTFE filter, and then it was taken in a clean $\mathrm{GC}$ vial for further analysis.

\subsection{Instrumental analysis}

The concentrated extracts were subjected to analysis by GC-2010 (Shimadzu) with Flame Thermionic Detector (FTD) for the detection of OPPs. The capillary column was AT-1 $(30 \mathrm{~m} \times 0.25 \mathrm{~mm} \times 0.25 \mu \mathrm{m})$ was used to separate the analytes. The split mode was used for injection, and the injector and detector temperature were $250^{\circ} \mathrm{C}$ and $280^{\circ} \mathrm{C}$ with a split ratio: $30: 0$. The column temperature was programmed as follows: from $150^{\circ} \mathrm{C}$ for $1 \mathrm{~min}$, from 150 to $220^{\circ} \mathrm{C}$ for 2 mins at $10^{\circ} \mathrm{C} /$ min. Helium was used as the carrier at a flow rate of 1.5 $\mathrm{mL} / \mathrm{min}$, and as a make-up gas at a flow rate of $30 \mathrm{~mL} /$ min for FTD with airflow at $145 \mathrm{~mL} / \mathrm{min}$. The flow rates of Helium and air were adjusted at $1.00 \mathrm{~Pa}$, with a total run time was 10 mins.

\subsection{Quality assurance procedure}

The experiment was validated on parameters of specificity, linearity, determination coefficient (R2), and limit of quantification (LOQ). The specificity was determined by specific retention time on the chromatogram for specific pesticide. The linearity and determination co-efficient was calculated continuously by standard fortified solutions of each pesticide at concentration levels ranged between 0.05 to $0.5 \mathrm{mg} / \mathrm{kg}$. The limit of quantification was calculated as the lowest detection level for each pesticide. The limit of quantitation (LOQ) was used to measure the sensitivity of the method.

\subsection{Health risk assessment}

The acute health indices (aHI) or short-term health risk to consumer (Equation 2) was measured using the estimated short-term intake (ESTI) (Equation 1) and the acute reference dose (ARfD). The chronic health risk/ hazard quotient or long-term health risk to consumers (HQ) (Equation 4) was measured using the estimated daily intake (EDI) (Equation 3) and the acceptable daily intake (ADI). The hazard quotient (HQ) indicates a potential risk if it reaches $100 \%$, and the higher aHI/HQ value is the higher risk. For the appropriate calculation, the ARfD and ADI values expressed as an $\mathrm{mg} / \mathrm{kg}$ of daily intake for a $60 \mathrm{~kg}$ person for seven organophosphorus pesticides were obtained from the Joint FAO/WHO Meeting on Pesticide Residues (JMPR) database (http://apps.who.int/pesticide-residues-jmprdatabase) (JMPR, 2004; FAO/WHO, 2019). According to $\mathrm{FAO} / \mathrm{WHO}$, the average national per capita consumption of $23 \mathrm{~g}$ of leafy vegetables, $89 \mathrm{~g}$ of nonleafy vegetables, and $14 \mathrm{~g}$ of fruit is an average of $126 \mathrm{~g}$ of fruit and vegetables per day in Bangladesh (Haque et al., 2014). The equation for calculation of ESTI, aHI, $\mathrm{HQ}$, and $\mathrm{cHI}$ were given below:

ESTI $=$ the highest residue level $\times$ food consumption/body weight

$\mathrm{aHI}=\mathrm{ESTI} / \mathrm{ARfD} \times 100 \%$

$\mathrm{EDI}=$ mean residue level $\times$ food consumption/body weight

$\mathrm{HQ}=\mathrm{EDI} / \mathrm{ADI} \times 100 \%$

\subsection{Statistical analysis}

The level of pesticide residue in collected samples was analysed and calculated in $\mathrm{mg} / \mathrm{kg}$ automatically by the Shimadzu GC software. All the data analyses and calculations were made by MS Excel 2013 software. 


\section{Results and discussion}

\subsection{Validation of the method}

In order to validate the method, recovery experiments were conducted for eggplant and cauliflower control samples. The collected control samples were cut into small pieces and stored at $-20^{\circ} \mathrm{C}$ until homogenization. Homogenization was done using a fruit blender. Then, the homogenized sample $(10 \mathrm{~g})$ was spiked prior to the determination procedure by the addition of a mixed pesticide standard working solution to prepare the fortification levels of $0.10 \mathrm{mg} / \mathrm{kg}$. After the addition of working standard solution in the matrix, the mixture was equilibrated by shaking and the samples were allowed to settle for 30 mins prior to extraction in order to ensure sufficient contact of the desired pesticides with the matrix. Then the samples were prepared according to the method which was described earlier. Precision in case of Repeatability $\left(\mathrm{RSD}_{\mathrm{r}}\right)$ was determined at the fortification levels of $0.10 \mathrm{mg} / \mathrm{kg}$. The average recoveries of the selected pesticides in eggplant ranged from $82-109 \%$ with RSD $\leq 9$, while in the case of cauliflower it was $80-98 \%$ with $\mathrm{RSD} \leq 8$. The linearity, determination coefficient $\left(\mathrm{R}^{2}\right)$, and LOQ were measured in an external standard solution using the peak areas obtained by GC-FTD analysis. The linear regression equation and determination coefficient $\left(\mathrm{R}^{2}\right)$ values and LOQ are given in Table 1. The standard curve results showed that the linearity was excellent, with a determination coefficient of $\mathrm{R}^{2}$ value ranges from 0.9931 -0.9998 . The limits of quantification (LOQs) were 0.01

Table 1. Linear regression parameters and LOQ of the seven selected organophosphorus pesticides in the external added standard solution.

\begin{tabular}{llcc}
\hline Name of pesticide & \multicolumn{1}{c}{ Linear equation } & $\mathrm{R}^{2}$ & $\mathrm{LOQ}$ \\
\hline Acephate & $\mathrm{y}=61799 \mathrm{x}+296.27$ & 0.9997 & 0.01 \\
Chlorpyrifos & $\mathrm{y}=59939 \mathrm{x}+400.27$ & 0.9993 & 0.01 \\
Diazinon & $\mathrm{y}=116230 \mathrm{x}+623.66$ & 0.9975 & 0.01 \\
Dimethoate & $\mathrm{y}=46574 \mathrm{x}-47.652$ & 0.9989 & 0.01 \\
Fenitrothion & $\mathrm{y}=103077 \mathrm{x}-204.12$ & 0.9998 & 0.01 \\
Malathion & $\mathrm{y}=38699 \mathrm{x}+602.34$ & 0.9931 & 0.01 \\
Quinalphos & $\mathrm{y}=81601 \mathrm{x}-351.52$ & 0.9991 & 0.01 \\
\hline
\end{tabular}

$\mathrm{R}^{2}=$ linear determination coefficient

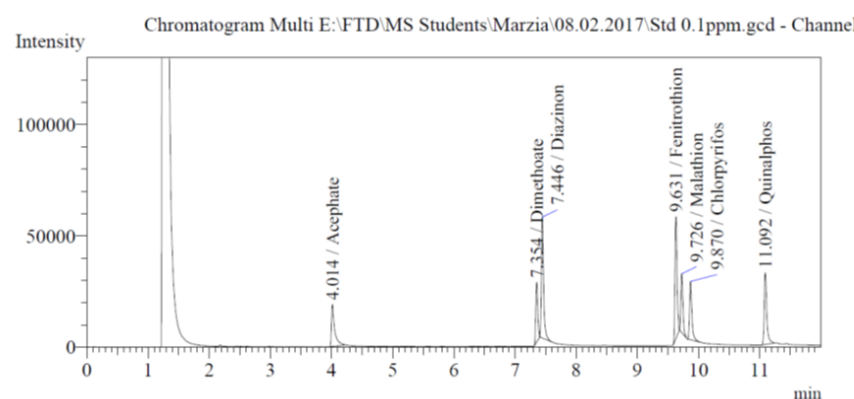

Figure 2. GC-FTD chromatogram of seven organophosphorus pesticides in external added standard spiked at $0.1 \mathrm{mg} / \mathrm{kg}$ $\mathrm{mg} / \mathrm{kg}$, indicating the high sensitivity of this method. The proposed method was applied to the external standard solution for assessing its specificity. The specificity of seven selected organophosphorus pesticides was performed by comparing the retention times of each pesticide presented in a typical chromatogram obtained by GC-FTD using analysis of external added standard solution and matrix solvent (Figure 2).

\subsection{Pesticide residues in eggplant}

Out of fifty samples of the eggplant, six samples $(12 \%$ of the total number of samples) contained chlorpyrifos residue, three samples $(6 \%$ of the total number of samples) contained dimethoate residue and one sample ( $2 \%$ of the total number of samples) contained diazinon residue (Table 2). All detected eggplant samples contained chlorpyrifos dimethoate and diazinon residues above the European Union maximum residue limit (EU-MRLs). In the eggplant, the most frequently detected pesticide was chlorpyrifos $(12 \%)$, followed by dimethoate $(6 \%)$. Among the seven OPPs, acephate, fenitrothion, malathion, and quinalphos were not detected in any eggplant samples collected from five major vegetable markets of Dhaka city. These findings are comparable to Islam et al. (2014). They collected forty-two eggplant, cauliflower, and country bean samples from the fields and markets of the Narsingdi district and were fifteen samples (over $36 \%$ of the total samples) found no OPPs (Islam et al., 2014). The study findings were well agreed with Hasan et al. (2017). In country bean samples collected from different Dhaka markets, they have detected two kinds of insecticides (such as dimethoate and quinalphos). Out of fifty analysed country bean samples, ten samples (20\%) contained dimethoate and quinalphos residues, five of which exceeded the maximum residue limits (MRLs). Most contaminated eight samples contained dimethoate residue (Hasan et al., 2017). Ahmed et al. (2017) analysed 170 samples collected from Jessore, Comilla, Narsingdi, Tangail, Rangpur, Jamalpur, Gazipur, and Dhaka for residue analysis in eggplant, yard long bean, bitter gourd, snake gourd, pointed gourd, okra, tomato, hyacinth bean, and cabbage samples. Among the one hundred seventy samples, $21.78 \%$ were contaminated with insecticides, either single or multiple residues, in which $18.26 \%$ of samples had residues above MRL (Ahmed et al., 2017).

According to Figure 3, chlorpyrifos was the most frequently detected pesticide followed by dimethoate in the eggplant samples collected from 5 major vegetable markets of Dhaka city. Out of the ten eggplant samples collected from the Jatrabari Bazar only one sample contained dimethoate residue $(0.08 \mathrm{mg} / \mathrm{kg})$. Among the ten eggplant samples collected from Mirpur-1 Bazar, two 
Table 2. Summary of pesticide residue analysis in the eggplant.

\begin{tabular}{|c|c|c|c|c|c|c|c|c|}
\hline \multirow{2}{*}{ Vegetable } & \multirow{2}{*}{ Pesticide } & \multicolumn{2}{|c|}{ No of the sample } & \multirow{2}{*}{$\begin{array}{c}\text { Detected } \\
\text { samples }(\%)\end{array}$} & \multirow{2}{*}{$\begin{array}{l}\mathrm{MRL}^{*} \\
(\mathrm{mg} / \mathrm{kg})\end{array}$} & \multirow{2}{*}{$\begin{array}{l}\text { No of samples } \\
>\text { MRL }(\mathrm{mg} / \mathrm{kg})\end{array}$} & \multirow{2}{*}{$\begin{array}{l}\text { Residual Range } \\
(\mathrm{mg} / \mathrm{kg})\end{array}$} & \multirow{2}{*}{$\begin{array}{c}\text { Mean residue } \\
(\mathrm{mg} / \mathrm{kg})\end{array}$} \\
\hline & & Analysed & Detected & & & & & \\
\hline \multirow{7}{*}{ Eggplant } & Acephate & 50 & 0 & & 0.01 & & & \\
\hline & Chlorpyrifos & 50 & 6 & 12 & 0.01 & 6 & $0.384-0.980$ & 0.669 \\
\hline & Diazinon & 50 & 1 & 2 & 0.01 & 1 & 0.01 & 0.01 \\
\hline & Dimethoate & 50 & 3 & 6 & 0.01 & 3 & $0.052-0.132$ & 0.088 \\
\hline & Fenitrothion & 50 & 0 & & 0.01 & & & \\
\hline & Malathion & 50 & 0 & & 0.02 & & & \\
\hline & Quinalphos & 50 & 0 & & 0.01 & & & \\
\hline
\end{tabular}

* According to the EU Pesticide Database (EC-396, 2005)

Table 3. Summary of pesticide residue analysis in the cauliflower.

\begin{tabular}{|c|c|c|c|c|c|c|c|c|}
\hline \multirow{2}{*}{ Vegetable } & \multirow{2}{*}{ Pesticide } & \multicolumn{2}{|c|}{ No of the sample } & \multirow{2}{*}{$\begin{array}{c}\text { Detected } \\
\text { samples (\%) }\end{array}$} & \multirow{2}{*}{$\begin{array}{l}\mathrm{MRL}^{*} \\
(\mathrm{mg} / \mathrm{kg})\end{array}$} & \multirow{2}{*}{$\begin{array}{l}\text { No of samples } \\
\text { >MRL }(\mathrm{mg} / \mathrm{kg})\end{array}$} & \multirow{2}{*}{$\begin{array}{l}\text { Residual Range } \\
\text { (mg/kg) }\end{array}$} & \multirow{2}{*}{$\begin{array}{c}\text { Mean residue } \\
(\mathrm{mg} / \mathrm{kg})\end{array}$} \\
\hline & & Analysed & Detected & & & & & \\
\hline \multirow{7}{*}{ Cauliflower } & Acephate & 50 & & & 0.01 & & & \\
\hline & Chlorpyrifos & 50 & 6 & 12 & 0.05 & 5 & $0.056-0.540$ & 0.345 \\
\hline & Diazinon & 50 & 4 & 8 & 0.01 & 4 & $0.033-0.42$ & 0.157 \\
\hline & Dimethoate & 50 & & & 0.02 & & & \\
\hline & Fenitrothion & 50 & & & 0.01 & & & \\
\hline & Malathion & 50 & & & 0.02 & & & \\
\hline & Quinalphos & 50 & 1 & 2 & 0.01 & 1 & 0.06 & 0.06 \\
\hline
\end{tabular}

* According to the EU Pesticide Database (EC-396, 2005)

samples contained chlorpyrifos residue $(0.470$ and 0.980 $\mathrm{mg} / \mathrm{kg}$ ), and two samples contained dimethoate residue $(0.052-0.132 \mathrm{mg} / \mathrm{kg})$. However, the ten samples collected from Mohammadpur Krishi Market 3 samples contained only chlorpyrifos residue $(0.384-0.762 \mathrm{mg} / \mathrm{kg})$, another sample contains chlorpyrifos $(0.920 \mathrm{mg} / \mathrm{kg})$ residue and dimethoate residue $(0.010 \mathrm{mg} / \mathrm{kg})$. Forty-one eggplant samples ( $82 \%$ of the total number of samples) contained no detectable residues of the sought pesticides.

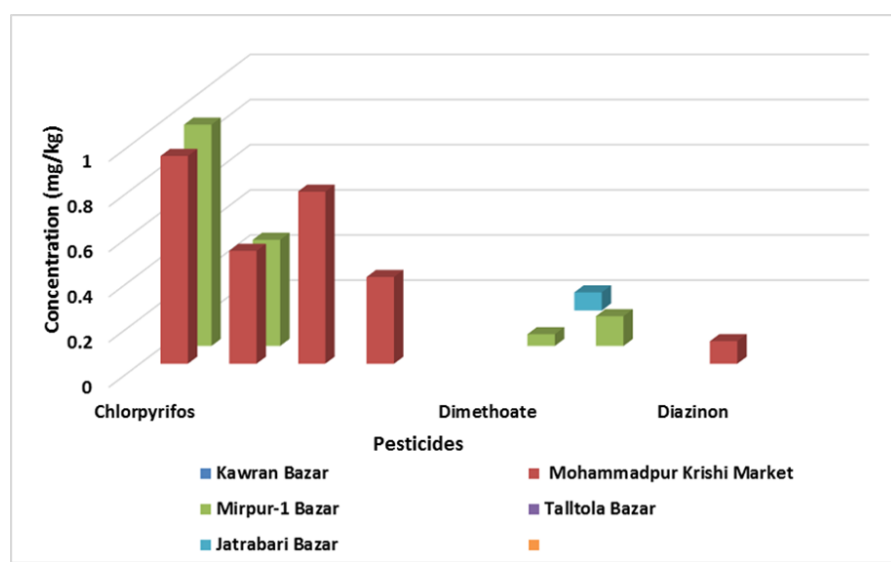

Figure 3. Frequency of organophosphorus pesticide residues with the amount in the eggplant collected from different markets of Dhaka city

\subsection{Pesticide residues in cauliflower}

Out of fifty samples of cauliflower, six samples $(12 \%$ of the total number of samples) contained chlorpyrifos residue, four samples $(8 \%$ of the total number of samples) contained diazinon residue and one sample $(2 \%$ of the total number of samples) contained quinalphos residue (Table 3). Out of 10 contaminated samples, 9 were above the European Union maximum residue limit (EU-MRLs). In the cauliflower, the most frequently detected pesticide was chlorpyrifos (12.00\%), followed by diazinon (8\%). Among the seven OPPs, acephate, dimethoate, fenitrothion, and malathion were not detected in any cauliflower samples. The findings of this study can also be compared to Akter et al. (2017). They found that $22 \%$ of samples contained pesticide residues of diazinon, dimethoate, quinalphos, and chlorpyrifos residues in eggplant collected from the Mymensingh district. Among the detected OPP residues, only five samples exceeded the MRL set by the EU (Aktar et al., 2017). The present study is in good agreement with Islam et al. (2019). They found that about $12 \%$ of bitter gourd samples were contaminated with different organophosphorus pesticides (Islam et al., 2019).

Figure 4 shows chlorpyrifos was the most frequently detected pesticide followed by diazinon and quinalphos in cauliflower samples. Out of ten cauliflower samples collected from the Jatrabari Bazar two contained multiples OPP residues namely chlorpyrifos $(0.03$ and $0.18 \mathrm{mg} / \mathrm{kg}$ ) and diazinon (0.094 and $0.42 \mathrm{mg} / \mathrm{kg}$ ). Among the ten eggplant samples collected from Mirpur1 Bazar, two samples contained chlorpyrifos $(0.373$ and $0.42 \mathrm{mg} / \mathrm{kg})$, and one sample contained diazinon $(0.033$ $\mathrm{mg} / \mathrm{kg}$ ). Another ten samples collected from Mohammadpur Krishi Market, two samples contained chlorpyrifos $(0.525$ and $0.54 \mathrm{mg} / \mathrm{kg})$, and one sample contained multiple residues namely diazinon $(0.08 \mathrm{mg} /$ 
$\mathrm{kg})$ and quinalphos $(0.06 \mathrm{mg} / \mathrm{kg})$. The forty-two cauliflower samples $(84 \%$ of the total number of samples) collected contained no detectable residues of the sought pesticides.

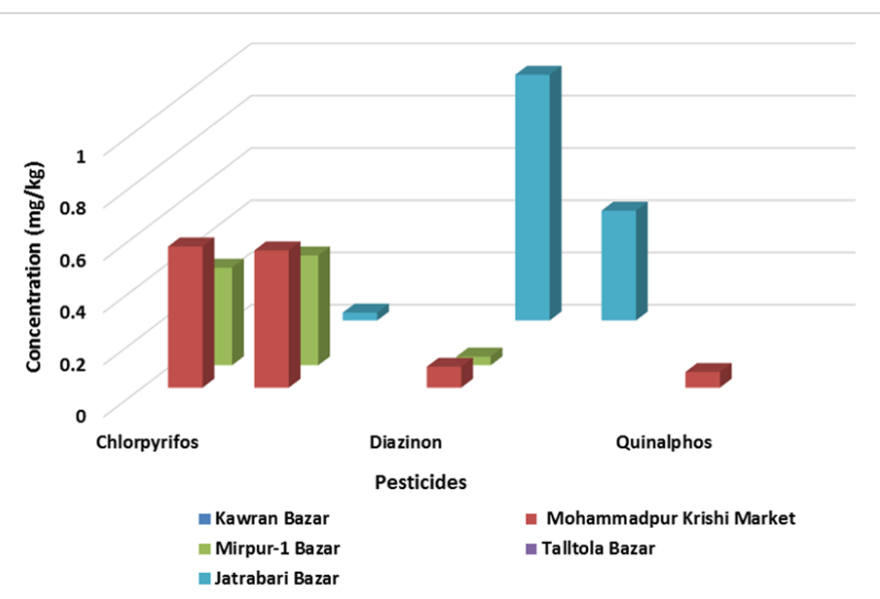

Figure 4. Frequency of organophosphorus pesticide residues with the amount in cauliflower collected from different markets of Dhaka city

\subsection{Risk assessment}

The mean concentrations of detected OPP pesticide residues were above their corresponding MRL levels (Table 2 and 3). The high-level residue in the eggplant samples of some OPPs is an indicator of the recent use of chlorpyrifos and dimethoate on eggplant farms especially vegetables grown and harvested very close to the city and surrounding areas. Unfortunately, these vegetables usually get high priced because they look fresh compared to vegetables that come from distant areas. The OPPs' health risk estimated in the eggplant samples were represented in Table 4. For acute or short-term risk (aHIs) analysis, all ESTI values were much lower than JMPR's ARfD values. Besides, the highest risk came from chlorpyrifos with aHI $1.454 \%$, followed by dimethoate with aHI $0.979 \%$. All the aHIs were so lower than $100 \%$, which indicates there was a negligible short- term or acute risk with the exposure to the tested pesticides via eggplant consumption.

Moreover, in the chronic or long-term risk assessment, the risk quotient (HQs) was notably higher than acute risk indexes. The (HQs) due to acephate, chlorpyrifos, diazinon, dimethoate, fenitrothion, and malathion in the eggplant was $0.025,9.931,0.297,6.527$, 0.148 , and 0.025 , respectively, suggesting that peoples in Dhaka city have no significant health risk through the consumption of eggplant since all the calculated values were less than $100 \%$.

Table 5 contains the acute and chronic health risk values for acephate, chlorpyrifos, diazinon, dimethoate, fenitrothion, and malathion in cauliflower. For acute or short-term risk assessment, all aHI values show much lower than $100 \%$ meaning that, there was a negligible short-term or acute risk with the exposure to the organophosphorus pesticides via cauliflower consumption. Same as in the chronic or long-term risk assessment. Hence, the health risk from organophosphorus pesticide residues in cauliflower was relatively smaller and they could not pose potential toxicity to the consumer. Moreover, it should be considered that these vegetable samples were analysed directly after collection without washing. Whereas, it is a common practice in Bangladesh to wash vegetable after buying and most of them also peeled and cooked before consumption. These washing, peeling and cooking practices will definitely reduce the amount of pesticide residues to a significant level (Panhwar et al., 2014; Jankowska et al., 2016; Alen et al., 2017; Prodhan et al., 2018). Therefore, it is important to consider for policymakers not to destroy these contaminated vegetable products. These samples are not allowed for international trade as fresh products due to higher MRL value but face no problem for national consumption especially when one-third of our population is suffering from malnutrition and sufficient food intake.

Table 4. The short-term and long-term risks due to the average daily intake of organophosphorus pesticides through eggplant consumption in Dhaka city. ARfD and ADI were adopted from the JMPR database.

\begin{tabular}{ccccccc}
\hline \multirow{2}{*}{ Pesticide } & \multicolumn{3}{c}{ Short-term risk } & \multicolumn{3}{c}{ Long-term risk } \\
\cline { 2 - 7 } & $\begin{array}{c}\text { ESTI } \\
(\mathrm{mg} / \mathrm{kg} / \mathrm{day})\end{array}$ & $\begin{array}{c}\text { ARfD } \\
(\mathrm{mg} / \mathrm{kg} / \mathrm{bw} / \text { day })\end{array}$ & $\begin{array}{c}\mathrm{aHI} \\
(\%)\end{array}$ & $\begin{array}{c}\text { EDI } \\
(\mathrm{mg} / \mathrm{kg} / \text { day })\end{array}$ & $\begin{array}{c}\text { ADI } \\
(\mathrm{mg} / \mathrm{kg} / \text { day })\end{array}$ & HQ \\
\hline Acephate & $7.42 \mathrm{E}-06$ & 0.1 & 0.007 & $7.42 \mathrm{E}-06$ & 0.03 & 0.025 \\
Chlorpyrifos & $1.45 \mathrm{E}-03$ & 0.1 & $\mathbf{1 . 4 5 4}$ & $9.93 \mathrm{E}-04$ & 0.01 & $\mathbf{9 . 9 3 1}$ \\
Diazinon & $1.48 \mathrm{E}-05$ & 0.03 & 0.049 & $1.48 \mathrm{E}-05$ & 0.005 & 0.297 \\
Dimethoate & $1.96 \mathrm{E}-04$ & 0.02 & $\mathbf{0 . 9 7 9}$ & $1.31 \mathrm{E}-04$ & 0.002 & $\mathbf{6 . 5 2 7}$ \\
Fenitrothion & $7.42 \mathrm{E}-06$ & 0.04 & 0.019 & $7.42 \mathrm{E}-06$ & 0.005 & 0.148 \\
Malathion & $7.42 \mathrm{E}-06$ & 0.3 & 0.002 & $7.42 \mathrm{E}-06$ & 0.03 & 0.025 \\
Quinalphos & - & - & - & $*$ & $*$ & - \\
\hline
\end{tabular}

*no authorized value for ARfD/ADI, and the corresponding risk index could not be computed. Potential values regarding health risk indicated as bold. 
Table 5. The short-term and long-term risks due to the average daily intake of organophosphorus pesticides through cauliflower consumption in Dhaka city. ARfD and ADI were adopted from the JMPR database.

\begin{tabular}{ccccccc}
\hline \multirow{2}{*}{ Pesticide } & \multicolumn{3}{c}{ Short-term risk } & \multicolumn{3}{c}{ Long-term risk } \\
\cline { 2 - 7 } & $\begin{array}{c}\text { ESTI } \\
(\mathrm{mg} / \mathrm{kg} / \mathrm{day})\end{array}$ & $\begin{array}{c}\text { ARfD } \\
(\mathrm{mg} / \mathrm{kg} / \mathrm{bw} / \text { day })\end{array}$ & $\begin{array}{c}\mathrm{aHI} \\
(\%)\end{array}$ & $\begin{array}{c}\text { EDI } \\
(\mathrm{mg} / \mathrm{kg} / \text { day })\end{array}$ & $\begin{array}{c}\text { ADI } \\
(\mathrm{mg} / \mathrm{kg} / \text { day })\end{array}$ & $\mathrm{HQ}$ \\
\hline Acephate & $7.42 \mathrm{E}-06$ & 0.1 & 0.007 & $7.42 \mathrm{E}-06$ & 0.03 & 0.025 \\
Chlorpyrifos & $8.01 \mathrm{E}-04$ & 0.1 & $\mathbf{0 . 8 0 1}$ & $5.12 \mathrm{E}-04$ & 0.01 & $\mathbf{5 . 1 2}$ \\
Diazinon & $6.23 \mathrm{E}-04$ & 0.03 & $\mathbf{2 . 0 7 7}$ & $2.33 \mathrm{E}-04$ & 0.005 & $\mathbf{4 . 6 6}$ \\
Dimethoate & $7.42 \mathrm{E}-06$ & 0.02 & 0.037 & $7.42 \mathrm{E}-06$ & 0.002 & 0.371 \\
Fenitrothion & $7.42 \mathrm{E}-06$ & 0.04 & 0.019 & $7.42 \mathrm{E}-06$ & 0.005 & 0.148 \\
Malathion & $7.42 \mathrm{E}-06$ & 0.3 & 0.002 & $7.42 \mathrm{E}-06$ & 0.03 & 0.025 \\
Quinalphos & - & - & - & $*$ & $*$ & - \\
\hline
\end{tabular}

*no authorized value for ARfD/ADI, and the corresponding risk index could not be computed. Potential values regarding health risk indicated as bold.

\section{Conclusion}

This study found that eggplant and cauliflower contained organophosphorus pesticide residues at a considerable level in major vegetable markets of the Dhaka city of Bangladesh. Among the 21 contaminated samples, 20 were above EU-MRL where chlorpyrifos was frequently detected. However, the short-term health risk or acute health indices (aHI) of organophosphorus pesticide residues by eggplant and cauliflower consumption was negligible. The observed levels of pesticide residues in the eggplant and cauliflower do not pose a serious risk to consumers, but pesticide contamination in vegetables may give rise to concern. Therefore, a routine monitoring system must be established to control the contamination of vegetables with pesticides especially vegetables grown and harvested very close to the city and surrounding areas.

\section{Conflict of interest}

The authors declare no conflict of interest.

\section{Acknowledgements}

We are very grateful to Md Kamal Hossain, Laboratory Technician in the pesticide analytical laboratory of Entomology Division, Bangladesh Agricultural Research Institute (BARI), for his cooperation to analyse the samples.

\section{References}

Ahmed, M.S., Begum, A., Rahman, M.A., Akon, M.W. and Chowdhury, M.A.Z. (2017). Extent of Insecticide Residue Load in Vegetables Grown under Conventional Farming in Bangladesh. The Agriculturists, 14(2), 38-47. https://doi.org/10.3329/ agric.v14i2.31346

Aktar, M.A., Khatun, R. and Prodhan, M.D.H. (2017). Determination of pesticide residues in eggplant using modified QuEChERS Extraction and Gas chromatography. International Journal of Agronomy and Agricultural Research, 11(2), 22-31.

Alen, Y., Adriyani, F., Suharti, N., Nakajima, S. and Djamaan, A. (2017). Determination of profenofos pesticide residue in tomato (Solanum lycopersicum L.) using GC technique. Scholars Research Library, 8(8), 137-141.

Amin, M., Miah, M., Rahman, H., Nancy, N. and Bhuiyan, M. (2018). Functional and group abundance of insects on eggplant. Bangladesh Journal of Agricultural Research, 43(4), 647-653. https://doi.org/10.3329/bjar.v43i4.39163

BARI. (2013). Bt brinjal. Bangladesh Agricultural Research Institute. Retrieved on April 30 from website: feedbacks $/ 40$

Chowdhury, M.T.I., Razzaque, M.A. and Khan, M.S.I. (2011). Chlorinated Pesticide Residue Status in Tomato, Potato and Carrot. Journal of Experimental Sciences, 2(1), 1-5.

Corbett, J.R. (1974). The biochemical mode of action of pesticides. London: Academic Press, 330pp. Retrieved on April 30, 2020 from https:// www.cabdirect.org/cabdirect/abstract/19742305756

Dasgupta, S., Meisner, C. and Huq, M. (2007). A Pinch or a Pint? Evidence of Pesticide Overuse in Bangladesh. Journal of Agricultural Economics, 58 (1), 91-114. https://doi.org/10.1111/j.14779552.2007.00083.x

EC-396. (2005). Maximum residue levels of pesticides in or on food and feed of plant and animal origin. Brussel, Belgium. Retrieved on May 15, 2020 from https://eur-lex.europa.eu/legal-content/EN/TXT/ PDF/?uri=CELEX:02005R0396-20160513

Espinoza-Navarro, O., Ponce-LaRosa, C. and BustosObregón, E. (2017). Organophosphorous Pesticides: Their Effects on Biosentinel Species and Humans. 
Control and Application in Chile. International Journal of Morphology, 35(3), 1069-1074. https:// doi.org/10.4067/S0717-95022017000300041

Eco, M. and Zweig G. (2018). Organophosphorus Pesticides, p. 1-387. CRC Press. Retrieved on April 30, 2020 from https://www.taylorfrancis.com/ books/9781351075305

FAO/WHO. (2019). Joint FAO/WHO Meeting on Pesticide Residues (JMPR) Context of the JMPR assessment. Summary Report Retrieved on April 30, 2020 from http://www.fao.org/3/ca4888en/ ca4888en.pdf

FAO/WHO. (2003). Diet, nutrition and the prevention of chronic diseases. Report of a joint FAO/WHO Export Consultation. Geneve. Retrieved on May 6, 2020 from http://www.fao.org/3/ag126e/ AG126E05.htm

González-Curbelo, M., Herrera-Herrera, A.V., RaveloPérez, L.M. and Hernández-Borges, J. (2012). Sample-preparation methods for pesticide-residue analysis in cereals and derivatives. Trends in Analytical Chemistry, 38, 32-51. https:// doi.org/10.1016/j.trac.2012.04.010

Grube, A., Donaldson, D., Kiely, T. and Wu, L. (2011). Pesticides Industry Sales and Usage: 2006 and 2007 Market Estimates. U.S. Environmental Protection Agency. Washington DC. Retrieved on May 6, 2020 from https://swap.stanford.edu/20140417081610/ http://www.epa.gov/opp00001/pestsales/07pestsales/ market estimates2007.pdf

Haque, M.M., Hassan, A.M., Islam, K., Bhuiyan, M.R., Shahi, M.S.J.R. and Lipi, P. (2014). Diet Intake Pattern and Nutritional Status of Rural Population in Bangladesh. Chattagram Maa-O-Shishu Hospital Medical College Journal, 13(2), 51-54. https:// doi.org/10.3329/cmoshmcj.v13i2.21065

Hasan, R., Prodhan, M.D.H., Rahman, S.M., Khanom, R. and Ullah, A. (2017). Determination of Organophosphorus Insecticide Residues in Country Bean Collected from Different Markets of Dhaka. Journal of Environmental and Analytical Toxicology, 7(4), 489-506. https:// doi.org/10.4172/2161-0525.1000489

Hassani, S., Momtaz, S., Vakhshiteh, F., Maghsoudi, A.S., Ganjali, M.R. and Norouzi, P. (2017). Biosensors and their applications in detection of organophosphorus pesticides in the environment. Archives of Toxicology, 91(1), 109-130. https:// doi.org/10.1007/s00204-016-1875-8

Herrera-Herrera, A.V., González-Sálamo, J., SocasRodríguez, B. and Hernández-Borges, J. (2019). Organophosphorus Pesticides (OPPs) in Bread and
Flours. In Preedy, V.R. and Watson, R.R. (Eds). Flour and Breads and their Fortification in Health and Disease Prevention. 2nd ed., p. 53-70. USA Press: Academic Press. https://doi.org/10.1016/B978 -0-12-814639-2.00005-8

Islam, M.S., Prodhan, M.D.H. and Uddin, M.K. (2019). Analysis of the pesticide residues in bitter gourd using modified QuEChERS extraction coupled with Gas Chromatography. Asia Pacific Environmental and Occupational Health Journal, 3(5), 6-15.

Islam, M.W., Dastogeer, K.M.G., Hamim, I., Prodhan, M.D.H. and Ashrafuzzaman, M. (2014). Detection and quantification of pesticide residues in selected vegetables of Bangladesh. Journal of Phytopathology and pest Management, 1(2), 17-30.

Islam, S., Afrin, N., Hossain, M.S., Nahar, N., Mosihuzzaman, M. and Mamun, M.I.R. (2009). Analysis of some pesticide residues in cauliflower by high performance liquid chromatography. American Journal of Environmental Sciences, 5(3), 325-329. https://doi.org/10.3844/ajessp.2009.325.329

Jankowska, M., Kaczynski, P., Hrynko, I. and Lozowicka, B. (2016). Dissipation of six fungicides in greenhouse-grown tomatoes with processing and health risk. Environmental Science Pollution Research International, 23, 11885-11900. https:// doi.org/10.1007/s11356-016-6260-x

JMPR. Pesticide Residues in Food. (2004). Toxicological evaluations. WHO pesticide residues series. Rome, Italy; 2004. Retrieved on April 30, 2020 from http://apps.who.int/iris/ bitstream/10665/43624/1/9241665203_eng.pdf

Joshi, S.C. and Sharma, P. (2011). Male reproductive toxicity of organophosphorus compounds: a review. Toxicological and Environmental Chemistry, 93(7), 1486-1507.

https:// doi.org/10.1080/02772248.2011.581874

Nahar, K.M., Khan, M.S.I., Habib, M., Hossain, S.M., Prodhan, M.D.H. and Islam, M.A. (2020). Health risk assessment of pesticide residues in vegetables collected from northern part of Bangladesh. Food Research, 4(6), 2281-2288. https://doi.org/10.26656/ fr.2017.4(6).309

Panhwar, A.A., Sheikh, S.A., Soomro, A.H. and Abro, G.H. (2014). Residue removal of pesticides from brinjal using different processing methods. Journal of Basic and Applied Science, 10, 431-438. https:// doi.org/10.6000/1927-5129.2014.10.57

Prodhan, M.D.H., Akon, M.W. and Alam, S.N. (2018). Decontamination of organophosphorus insecticide residues from eggplant and yard long bean. International Journal of Experimental Agriculture, 8 
(1), 6-9.

Prodhan, M.D.H., Papadakis, E.N. and PapadopoulouMourkidou, E. (2015). Determination of Multiple Pesticide Residues in Eggplant with Liquid Chromatography-Mass Spectrometry. Food Analytical Methods, 8(1), 229-235. https:// doi.org/10.1007/s12161-014-9898-3

Srinivasan, R. (2008). Integrated pest management for eggplant fruit and shoot borer (Leucinodes orbonalis) in South and Southeast Asia: past, present and future. Journal of Biopesticides, 1(2), 105-112.

Sultana, P. and Nakagoshi, N. (2001). An analysis of pesticide used for rice pest management in Bangladesh. Journal of International Development and Cooperation, 8(1), 107-126.

Yuan, Y., Chen, C., Zheng, C., Wang, X., Yang, G. and Wang, Q. (2014). Residue of chlorpyrifos and cypermethrin in vegetables and probabilistic exposure assessment for consumers in Zhejiang Province, China. Food Control, 36(1), 63-68. https:// doi.org/10.1016/j.foodcont.2013.08.008 